
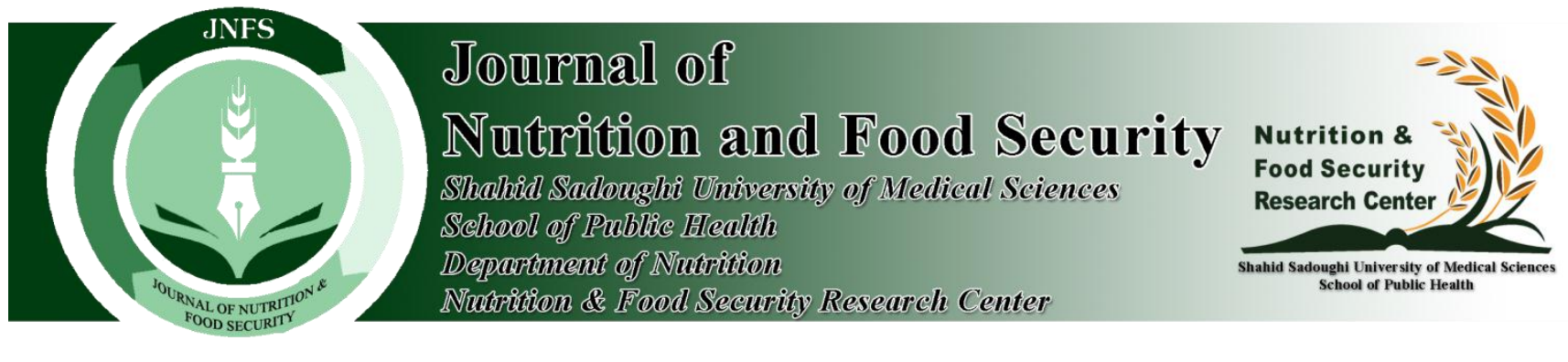

eISSN: 2476-7425

pISSN: 2476-7417

JNFS 2019; 4(1): 43-57

Website: jnfs.ssu.ac.ir

\title{
Effects of Paleolithic Diet on Glucose Control in Adults: A Systematic Review and Meta-analysis of Controlled Clinical Trials
}

Mohammad Mohammadi; MSc ${ }^{1,2}$, Hamed Mohammadi; MSc ${ }^{3,4}$, Ehsan Ghaedi; BSc ${ }^{5}$, Nahid Ramezani-Jolfaie; MSc ${ }^{1,2^{*}}$ \& Amin Salehi-Abargouei; PhD ${ }^{1,2}$

${ }^{1}$ Nutrition and Food Security Research Center, Shahid Sadoughi University of Medical Sciences, Yazd, Iran.

${ }^{2}$ Department of Nutrition, School of Public Health, Shahid Sadoughi University of Medical Sciences, Yazd, Iran.

${ }^{3}$ Food Security Research Center, School of Nutrition and Food Science, Isfahan University of Medical Sciences, Isfahan, Iran.

${ }^{4}$ Students' Research Committee, Isfahan University of Medical Sciences, Isfahan, Iran.

5 Department of Cellular and Molecular Nutrition, School of Nutritional Sciences and Dietetics, Tehran University of Medical Sciences, Tehran, Iran.

\begin{tabular}{l}
\hline ARTICLE INFO \\
\hline SYSTEMATIC REVIEW \\
and META-ANALYSIS \\
ARTICLE \\
\hline Article history: \\
Received: 12 Dec 2018 \\
Revised: 3 Mar 2018 \\
Accepted: 26 May 2018 \\
\\
\hline *Corresponding author: \\
Ramezani.n.j@ gmail.com \\
PhD candidate in Nutritional \\
Sciences, Department of \\
Nutrition, School of Public \\
Health, Shahid Sadoughi \\
University of Medical \\
Sciences, Yazd, Iran. \\
Postal code: 1449614535 \\
Tel: +98-35- 31492136 \\
\hline
\end{tabular}

\begin{abstract}
Background: Although the results were conflicting, the Paleolithic diet (PD) was proposed to be effective in improvement of metabolic status. We aimed to conduct a systematic review and meta-analysis on the randomized controlled clinical trials (RCTs) evaluating the effects of PD on glycemic markers. Methods: Online databases such as PubMed, Scopus, Web of Science, and Google Scholar were searched up to December 2017 without any restrictions. The weighted mean difference (WMD) was also calculated using random effects model. Results: Eventually, eight good quality studies were included in the present systematic review and meta-analysis. The pooled analysis showed that although adherence to the PD led to reduction of fasting blood glucose (FBG) concentrations, it was no statistically significant (WMD $=-0.31,95 \%$ CI: $-0.70,0.07, P=0.11)$. Moreover, compared with the control diets, the PD consumption did not significantly affect other glycemic markers such as 2-h post-prandial blood glucose (2h PBG), insulin, homeostasis model assessment for insulin resistance (HOMA-IR), and Hemoglobin A1c (HbA1c). Conclusions: Adherence to the PD had no significant effect on the glycemic markers, but reduction was observed in FBG levels.
\end{abstract}

Keywords: Paleolithic diet; Glycemic markers; Systematic review; Metaanalysis.

\section{Introduction}

Type 2 diabetes mellitus (T2DM), one of the most serious current health problems, is a chronic metabolic disease characterized by persistent hyperglycemia due to deficiencies in 
insulin production and/or insulin resistance (IR) (Ahangarpour et al., 2017). The prevalence of diabetes was estimated to be 9 percent in 2014 among adults (WHO, 2014). Based on the predictions from world health organization (WHO), the global prevalence of T2DM will rise from 171 million in 2000 to 366 million people by 2030 (Parham et al., 2014). Prolonged increased glucose level in T2DM causes many microvascular and macro-vascular complications such as neuropathy, retinopathy, nephropathy, and cardiovascular disorders. It also increases mortality and morbidity among the patients (Ahangarpour et al., 2017, Chan and Tang, 2015).

It has been recommended that the fasting blood glucose (FBG), 2-h post-prandial blood glucose ( $2 \mathrm{~h}$ PBG), and hemoglobin A1c (HbA1c) could be considered as the standard glycemic markers for the assessment of T2DM and pre-diabetes status (Carson et al., 2016). Moreover, homeostasis model assessment, as a useful clinical index, has been widely used to evaluate the insulin resistance (HOMA-IR) (Qu et al., 2011).

Diet modification is considered as one of the cornerstones in T2DM management, but we are faced with paucity of evidences about the appropriate approach for controlling hyperglycemia (Association, 2016). Moreover, there is uncertainty concerning the caloric intake from carbohydrate, fat, and protein for patients with T2DM (Evert et al., 2014). A wide variety of dietary patterns must be investigated to manage glycemic control and T2DM and to protect against its complications.

Today, the dietary pattern taken by our ancestors during the Paleolithic era has been focused by many researchers (the 'Old Stone Age,' 2.5 million10,000 years ago). Anthropologic evidence from fossils, archeological evidence, and existing huntergatherer tribes around the world revealed that the ancient hunter-gatherer humans had Paleolithic diet (PD) (Whalen et al., 2017). This diet is described as a mainly plant food-based diet, with a wide variety of vegetables, roots, nuts, fruits, lean meat, fish, and eggs but not grains, dairy products, processed foods, sugars, and added salt (Jönsson et al., 2009). The PDs are naturally lower in sodium content while higher in potassium, antioxidants, vitamins $\mathrm{C}$ and $\mathrm{E}$, carotenes, micronutrients, and fiber (Cordain, 2002, Österdahl et al., 2008).

Studies of extant hunter-gatherer people around the world such as Kitava, Papua New Guinea showed low prevalence of degenerative diseases among them (Metzgar et al., 2011). It was also indicated that this diet could be appropriate to prevent insulin resistance and glucose intolerance (Lindeberg et al., 2003). Therefore, research topics such as the clinical importance of PD pattern and models of disease prevention were discussed in the literature.

Although a number of randomized controlled clinical trials (RCTs) have been recently published on the effects of PD, we are still faced with lack of research evidence regarding its clinical benefits. Studies which systematically reviewed the current evidences are also scarce. Therefore, the aim of present systematic review and meta-analysis of published RCTs was to evaluate the effect of the PD pattern on the glycemic indices and to quantify its possible hypoglycemic effects.

\section{Materials and Methods}

Search strategy: This study was designed in accordance with the preferred reporting items for systematic reviews and meta-analyses (PRISMA) statement (Picot et al., 2012). An in-depth search was carried out to identify the related published literature throughout the databases of PubMed, ISI Web of Science, Scopus, and Google Scholar databases up to December 2017 using the following key words: "Paleolithic diet", "Paleolithic nutrition", stone age diet", "stone age nutrition", "caveman diet", "caveman nutrition", "Hunter-Gatherer diet", "Hunter-Gatherer nutrition", Paleolithic-type diet", Paleolithic-type nutrition". 
Study selection: Titles and abstracts of all articles retrieved from the initial search were evaluated independently by two reviewers (Mohammadi M and Mohammadi $\mathrm{H}$ ). The original studies were included if they met the following inclusion criteria: (1) applied a randomized-controlled clinical trial design; (2) were conducted among human adults (aged $\geq 18$ years); (2) investigated the impact of the PD on glycemic status; and (3) reported the sufficient information on serum glycemic biomarkers in both Paleolithic and control diet. Articles that did not meet the inclusion criteria were excluded using a screen check list with a hierarchical approach. Exclusion criteria were: (1) uncontrolled trials; (2) participants aged $<18$ years; (3) use of other interventions such as exercise along with the PD; (4) experimental studies; and (5) reviews, letters, editorial articles, or case reports. In the case that several papers reported similar data, we used the study with the largest population group.

Data extraction: The required data were extracted from the eligible studies: first author's name; publication year; research design; gender and age of participants; sample size, duration of intervention, as well as the type of intervention and control diets. Furthermore, the mean and standard deviation (SD) of indices related to glycemic control and insulin resistance were extracted at baseline and end of study. The extracted data were checked by three independent researchers (Mohammadi M, Mohammadi $\mathrm{H}$ and Ramezani-Jolfaie $\mathrm{N}$ ) and rechecked by other authors to diminish the possible errors.

Quality assessment: A systematic assessment of bias was conducted on the included studies using the Cochrane criteria by two reviewers (Mohammadi M and Mohammadi H) (Higgins and Green, 2011). The quality of all included studies was assessed by the following items: adequacy of sequence generation, allocation concealment, blinding, illuminating of dropouts (imperfect outcome data), selective outcome reporting, and other potential causes of bias. Based on the Cochrane Handbook recommendations, a judgment of "yes" was considered as low risk of bias, "no" was perceived as high risk of bias, and "unclear" was taken as blurred or unidentified risk of bias. If RCTs had low risk in two risk domains or two to four risk domains, they were considered to have fair and high quality, respectively.

Data analysis: For each glycemic control index, we calculated the mean (SD) at the baseline and after the intervention for the PD and control groups. To calculate the pooled effect size for FBG, 2h PBG, insulin, HOMA-IR, and $\mathrm{HbA1c}$, we used the random effects model. Between-study heterogeneity was evaluated using Cochran's Q test and I-square $\left(I^{2}\right)$. To evaluate the possible effects of individual studies on the final results, an influence analysis was conducted (Tobias, 1999). We also used Begg's rank correlation test and Egger's regression asymmetry test to evaluate the publication bias. Statistical analysis was performed using STATA, version 11.2 (Stata Corp, College Station, TX). The statistical significant values were defined as $P$ values $<0.05$

\section{Results}

Study selection: The electronic search on literature yielded 2722 titles, of which 26 were reviewed in full text considering the criteria of eligibility. Of these studies, 19 papers were excluded for the following reasons: 1) seven studies reported no data related to our target outcomes (Baumgartner et al., 2009, Frassetto et al., 2013, Genoni et al., 2016a, Jonsson et al., 2010, Jonsson et al., 2013, Lee et al., 2017, Singh et al., 2012); 2) six studies reported duplicated results (Andersson et al., 2016, Blomquist et al., 2017a, Blomquist et al., 2017b, Boraxbekk et al., 2015, Sandberg et al., 2012, Stomby et al., 2015); 3) four studies had single-arm design with no control group (Frassetto et al., 2009, Osterdahl et al., 2008, Ryberg et al., 2013, Trexler et al., 2013); 4) one study evaluated the effect of PD along with exercise (Otten et al., 
2016b); and 5) one study evaluated the acute effects of following the PD consumption (Bligh et al., 2015). In addition, one additional study (Mellberg et al., 2014) was added after the manual search of references. Eventually, eight eligible studies were included in the present systematic review and metaanalysis (Boers et al., 2014, Chorell et al., 2016, Genoni et al., 2016b, Jönsson et al., 2009, Lindeberg et al., 2007, Masharani et al., 2015, Mellberg et al., 2014, Otten et al., 2016a). The study selection process is shown in Figure 1.

Study characteristics: The included studies were published from 2007 to 2016 and were conducted in the United States (Masharani et al., 2015), Australia (Genoni et al., 2016b), Sweden (Chorell et al., 2016, Jönsson et al., 2009, Lindeberg et al., 2007, Mellberg et al., 2014, Otten et al., 2016a), and Netherlands (Boers et al., 2014). Seven trials were designed as parallel-group studies (Boers et al., 2014, Chorell et al., 2016, Genoni et al., 2016b, Lindeberg et al., 2007, Masharani et al., 2015, Mellberg et al., 2014, Otten et al., 2016a) and one study had a crossover design (Jönsson et al., 2009) with follow-up period of two weeks to two years. All studies were comparison trials, in which PD was compared with other dietary patterns. In these studies, guidelines such as Australian guide to healthy eating (AGHE), Nordic nutrition recommendations (NNR), dietary recommendations based on the guidelines of the American Diabetes Association (ADA), dietary recommendations based on the guidelines for a healthy diet of the Dutch Health Council, diabetes diet designed in accordance with current diabetes dietary guideline, and Consensus (Mediterranean-like) diet were applied.

The number of samples in these RCTs ranged from 13 to 61 participants with the mean age of 59 years. The participants had different health status including healthy people, postmenopausal women, patients with type 2 diabetes or ischemic heart disease, and individuals with characteristics of the metabolic syndrome. The characteristics of the included RCTs in the present systematic review and meta-analysis are listed in Table 1.

Risk of bias assessment: After evaluating the quality of eight final studies according to the Cochrane collaboration's risk of bias assessment tool, all RCTs were of good quality (Boers et al., 2014, Chorell et al., 2016, Genoni et al., 2016b, Jönsson et al., 2009, Lindeberg et al., 2007, Mellberg et al., 2014, Otten et al., 2016a) except Masharani et al.'s study (Masharani et al., 2015). This study had fair quality, in which no methods of allocation concealment and random sequence generation were reported. Moreover, since blinding was not possible to conduct dietary intervention trials, the blinding of participants and investigators was not considered throughout these studies. Findings of the quality assessment are illustrated in Table 2.

Meta-analysis: Six studies (including 210 participants) (Boers et al., 2014, Genoni et al., 2016b, Jönsson et al., 2009, Lindeberg et al., 2007, Masharani et al., 2015, Mellberg et al., 2014) examined the effect of PD pattern on FBG levels. The overall results showed that although adherence to PD led to reduction of FBG concentrations, it was not statistically significant [weighted mean difference $(\mathrm{WMD})=-0.31,95 \%$ confidence interval (CI): $-0.70, \quad 0.07, \quad P=0.11$; Figure 2]. No heterogeneity was found between the studies $(\mathrm{Q}$ statistic $=5.78$, Cochrane $\mathrm{Q}$ test, $P=0.328, \mathrm{I}^{2}=$ $13.5 \%)$.

Five studies (including 186 participants) reported the effects of PD on serum insulin changes. Their results showed that PD consumption did not significantly affect the insulin levels in comparison with the control diets (WMD $=0.55,95 \% \mathrm{CI}:-1.81$, 2.92, $P=0.647$; Figure 3). The result of betweenstudy heterogeneity was significant (Cochran's Q test, $\mathrm{Q}$ statistic $=18.49, P=0.001, \mathrm{I}^{2}=78.4 \%$ ); however, due to the limited number of studies, we could not perform subgroup analysis to find the potential sources of this heterogeneity. 
The overall result of meta-analysis of four studies (including 131 participants) (Boers et al., 2014, Chorell et al., 2016, Jönsson et al., 2009, Lindeberg et al., 2007) over the effects of the PD adherence on HOMA-IR showed no significant change (WMD = 0.33, 95\%CI: $-0.76,0.09, P=0.126$; Figure 4) and no between-study heterogeneity (Cochran's Q test, Q statistic $\left.=4.42, P=0.219, \mathrm{I}^{2}=32.2 \%\right)$.

Other outcomes such as HbA1c and 2h PBG were also reported in a few of studies; no significant results were observed after conducting the metaanalysis (HbA1c: WMD $=-0.26,95 \% \mathrm{CI}:-0.73,0.20$, $P=0.274$; 2h PBG: WMD $=-1.49$, 95\%CI: -3.16 , $0.16, P=0.077)$. Furthermore, no heterogeneity was observed among the studies (HbAlc: Cochran's Q test, $\mathrm{Q}$ statistic $=0.05, P=0.977, \mathrm{I}^{2}=0 \% ; 2 \mathrm{~h}$ PBG:
Cochran's Q test, Q statistic $=3.30, P=0.069, \mathrm{I}^{2}=$ $69.7 \%)$.

Sensitivity analysis and publication bias: The sensitivity analysis was conducted for all parameters to assess the contribution of each study on the overall estimate. The results did not change after excluding any other study.

We found no evidence of publication bias in studies evaluating the effect of PD consumption on the levels of FBG (Begg's test, $P=0.707$; Egger's test, $P=0.997$ ), insulin (Begg's test, $P=0.806$; Egger's test, $\mathrm{P}=0.534$ ), HOMA-IR (Begg's test, $\mathrm{P}=$ 0.308; Egger's test, $P=0.071$ ), and HbAlc (Begg's test, $P=0.296$; Egger's test, $P=0.154$ ).

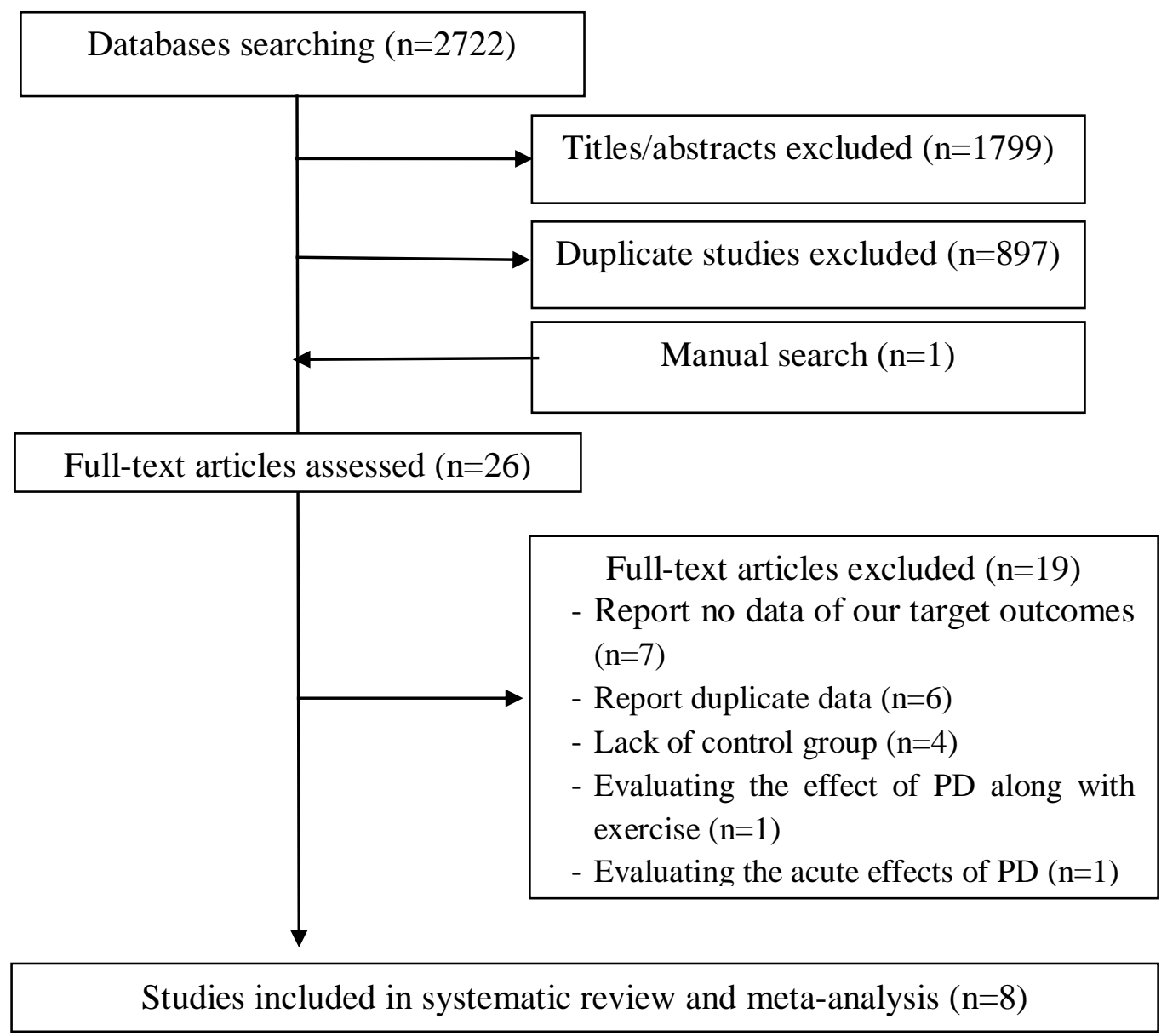

Figure 1. Flow chart representing study selection process. 


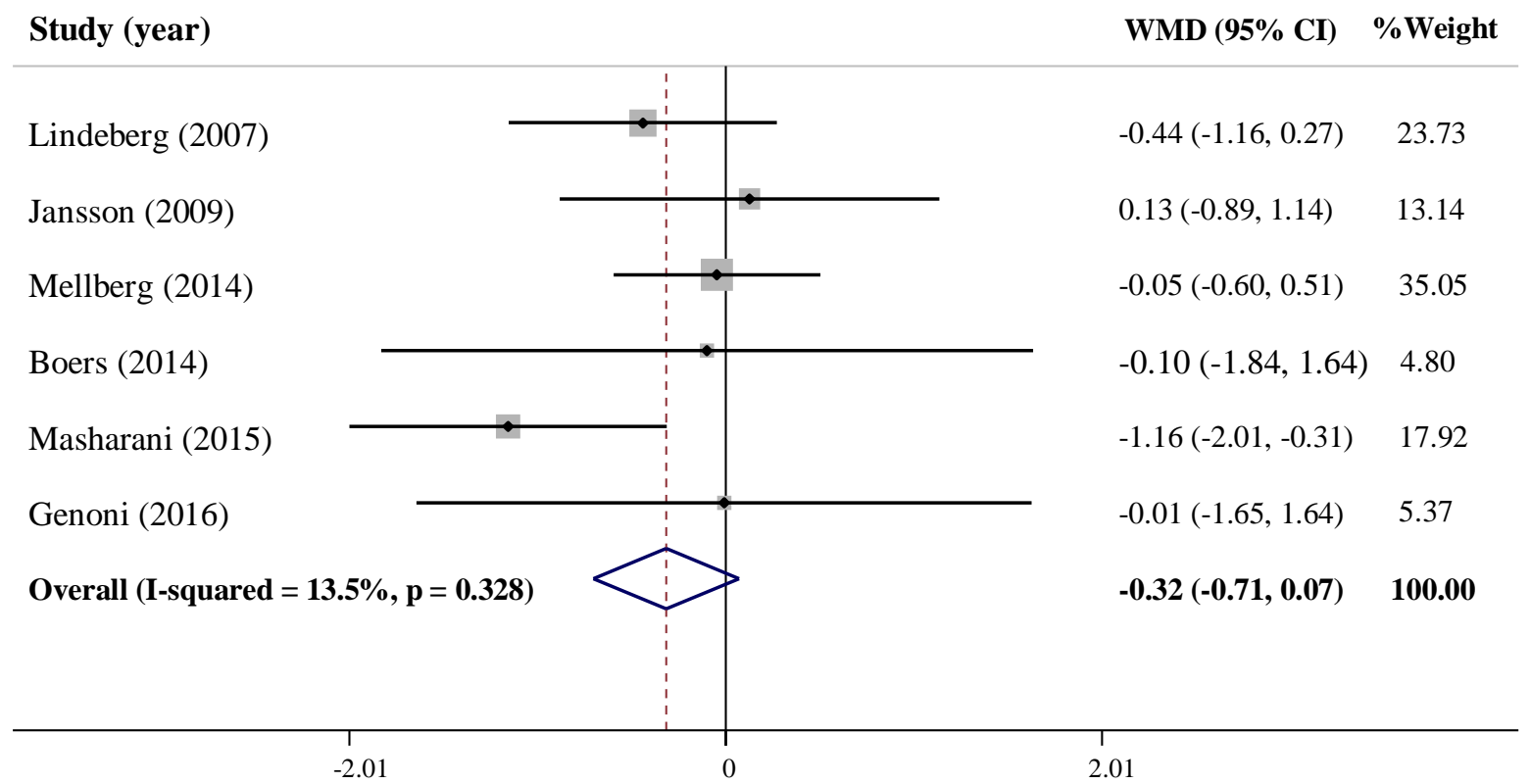

Figure 2. Forest plot of RCTs representing weighted mean difference in glucose change between the Paleolithic diet and control groups for all included studies.

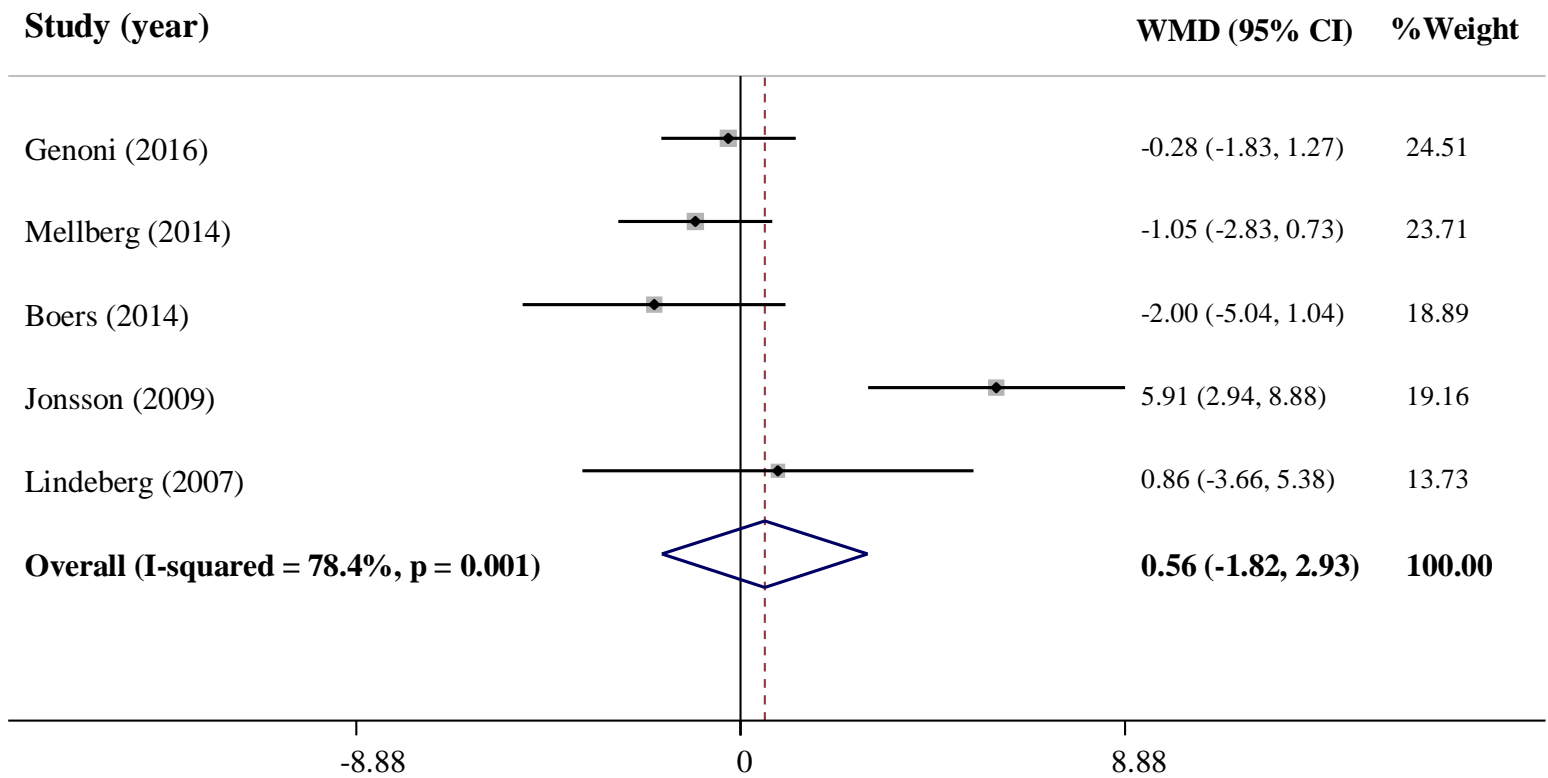

Figure 3. Forest plot of RCTs representing weighted mean difference in insulin change between the Paleolithic diet and control groups for all included studies. 
Study (year)

Chorell (2016)

Boers (2014)

Jonsson (2009)

Lindeberg (2007)

Overall $(\mathrm{I}$-squared $=32.2 \%, \mathrm{p}=\mathbf{0 . 2 1 9})$
WMD (95\% CI) \% Weight

$-0.09(-0.62,0.43) \quad 35.96$

$-0.36(-1.02,0.30) \quad 27.28$

$-1.42(-2.57,-0.27) \quad 11.81$

$-0.15(-0.86,0.56) \quad 24.95$

$-0.34(-0.77,0.09) \quad 100.00$

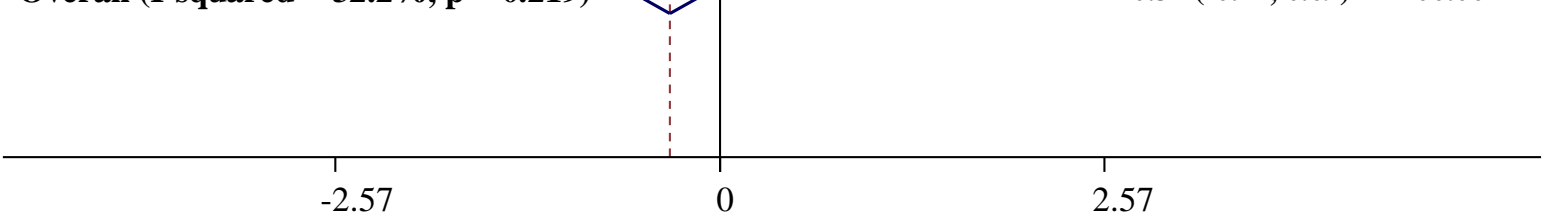

Figure 4. Forest plot of RCTs representing weighted mean difference in HOMA-IR change between the Paleolithic diet and control groups for all included studies. 
Table 1. Characteristics of included randomized controlled clinical trials in the systematic review

\begin{tabular}{|c|c|c|c|c|c|c|c|c|c|}
\hline 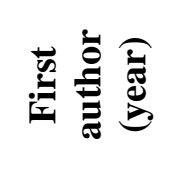 & 己̇ & 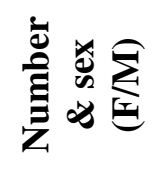 & 馬 & 论烦 & 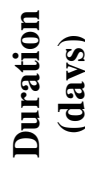 & 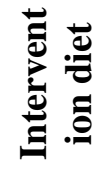 & 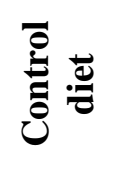 & ت & 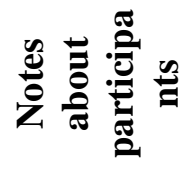 \\
\hline
\end{tabular}

\begin{tabular}{|c|c|c|c|c|c|c|c|c|c|}
\hline $\begin{array}{l}\text { Genoni } \\
(2016)\end{array}$ & 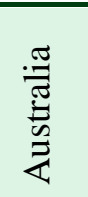 & 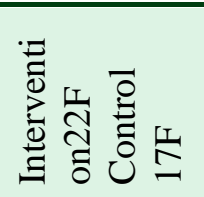 & 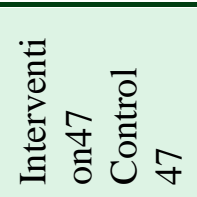 & 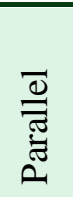 & $\stackrel{\infty}{\sim}$ & $\begin{array}{l}\text { Paleolithic diet } \\
\text { CHO: } 27.8 \% \text {, Fat: } \\
\text { 39.8\%, Pro: } 26.8 \%\end{array}$ & $\begin{array}{l}\text { Australian Guide to } \\
\text { Healthy Eating } \\
\text { CHO: } 40.6 \% \text {, Fat: } 32.6 \% \text {, } \\
\text { Pro: } 21.7 \%\end{array}$ & $\begin{array}{l}\text { FBG } \\
\text { Insulin }\end{array}$ & Healthy women \\
\hline $\begin{array}{l}\text { Chorell } \\
(2016)\end{array}$ & 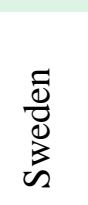 & 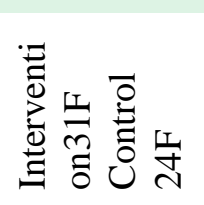 & 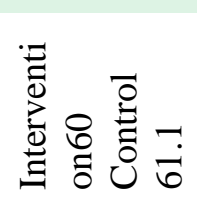 & $\frac{\bar{\Xi}}{\bar{\pi}}$ & $\stackrel{\infty}{\infty}$ & $\begin{array}{l}\text { Paleolithic diet } \\
\text { CHO: } 30 \% \text {, Fat: } 40 \% \\
\text { Pro: } 30 \%\end{array}$ & $\begin{array}{l}\text { Nordic Nutrition } \\
\text { Recommendations } \\
\text { CHO: } 55-60 \% \text {, Fat: } 25- \\
\text { 30\%, Pro: } 15 \%\end{array}$ & $\begin{array}{l}\text { HOMA- } \\
\text { IR }\end{array}$ & $\begin{array}{l}\text { Postmenopausal non- } \\
\text { smoking women with a } \\
\mathrm{BMI} \geq 27 \mathrm{~kg} / \mathrm{m}^{2}\end{array}$ \\
\hline $\begin{array}{l}\text { Otten } \\
(2016)\end{array}$ & $\begin{array}{l}\frac{\bar{d}}{0} \\
\vdots \\
\vdots \\
\vdots\end{array}$ & 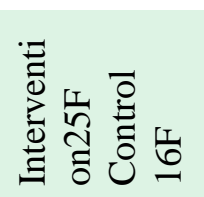 & 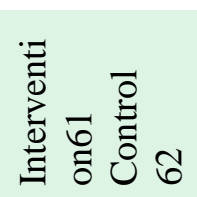 & 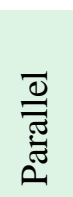 & $\stackrel{\infty}{\infty}$ & $\begin{array}{l}\text { Paleolithic diet } \\
\text { CHO: } 30 \% \text {, Fat: } 40 \% \\
\text { Pro: } 30 \%\end{array}$ & $\begin{array}{l}\text { Nordic Nutrition } \\
\text { Recommendations } \\
\text { CHO: } 55-60 \% \text {, Fat: } 25- \\
\text { 30\%, Pro: } 15 \%\end{array}$ & 2h PBG & $\begin{array}{l}\text { Postmenopausal non- } \\
\text { smoking women with a } \\
\text { BMI } \geq 27 \mathrm{~kg} / \mathrm{m}^{2}\end{array}$ \\
\hline $\begin{array}{l}\text { Masharani } \\
(2015)\end{array}$ & $\underset{\mathscr{D}}{\mathbb{D}}$ & 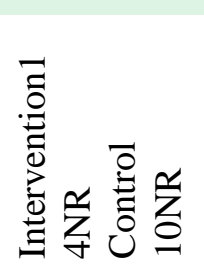 & 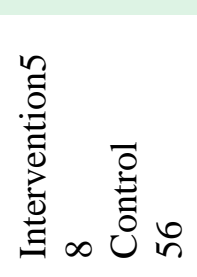 & $\frac{\bar{\Xi}}{\bar{\pi}}$ & $\vec{\sim}$ & $\begin{array}{l}\text { Paleolithic diet } \\
\text { CHO: } 58.2 \% \text {, Fat: } \\
27 \% \text {, Pro: } 18.5 \%\end{array}$ & $\begin{array}{l}\text { A diet based on } \\
\text { recommendations by the } \\
\text { American Diabetes } \\
\text { Association } \\
\text { CHO: } 54.4 \% \text {, Fat: } 28.8 \% \text {, } \\
\text { Pro: } 20.3 \%\end{array}$ & $\begin{array}{l}\text { FBG } \\
\text { HbA1c }\end{array}$ & $\begin{array}{l}\text { Patients with type } 2 \\
\text { diabetes }\end{array}$ \\
\hline $\begin{array}{l}\text { Mellberg } \\
\text { (2014) }\end{array}$ & $\begin{array}{l}\frac{0}{0} \\
\frac{8}{3} \\
\vdots\end{array}$ & 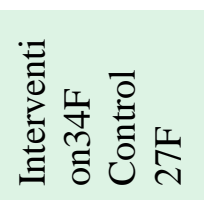 & 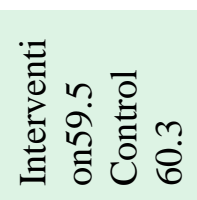 & $\frac{\bar{\sigma}}{\bar{\pi}}$ & 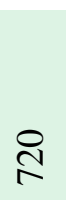 & $\begin{array}{l}\text { Paleolithic diet } \\
\text { CHO: } 30 \% \text {, Fat: } 40 \% \\
\text { Pro: } 30 \%\end{array}$ & $\begin{array}{l}\text { Nordic nutrition } \\
\text { recommendations } \\
\text { CHO: } 55-60 \% \text {, Fat: } 25- \\
30 \% \text {, Pro: } 15 \%\end{array}$ & $\begin{array}{l}\text { FBG } \\
\text { Insulin }\end{array}$ & $\begin{array}{l}\text { Postmenopausal non- } \\
\text { smoking women with a } \\
\text { BMI } \geq 27 \mathrm{~kg} / \mathrm{m}^{2}\end{array}$ \\
\hline $\begin{array}{l}\text { Boers } \\
(2014)\end{array}$ & 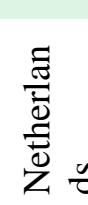 & 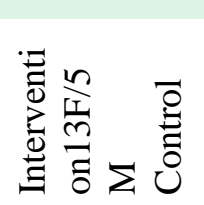 & 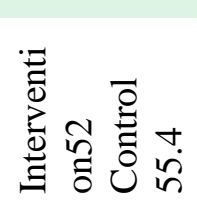 & 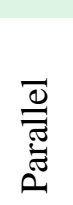 & $\Xi$ & $\begin{array}{l}\text { Paleolithic diet } \\
\text { CHO: } 32 \% \text {, Fat: } 41 \% \\
\text { Pro: } 24 \%\end{array}$ & $\begin{array}{l}\text { Healthy reference diet } \\
\text { CHO: } 50 \% \text {, Fat: } 29 \% \\
\text { Pro: } 17 \%\end{array}$ & $\begin{array}{l}\text { FBG } \\
\text { Insulin } \\
\text { HOMA- } \\
\text { IR }\end{array}$ & $\begin{array}{l}\text { Subjects with } \\
\text { characteristics of the MetS }\end{array}$ \\
\hline
\end{tabular}




\begin{tabular}{|c|c|c|c|c|c|c|c|c|c|}
\hline $\begin{array}{l}\text { Jonsson } \\
\text { (2009) }\end{array}$ & $\begin{array}{l}\frac{\pi}{0} \\
\frac{\pi}{0} \\
\text { हn }\end{array}$ & 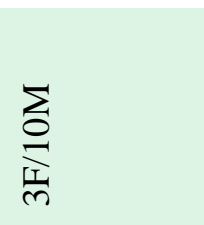 & ț & $\begin{array}{l}\overline{0} \\
\grave{0} \\
0 \\
0 \\
0 \\
0\end{array}$ & \& & $\begin{array}{l}\text { Paleolithic diet } \\
\text { CHO: } 32 \% \text {, Fat: } \\
39 \% \\
\text { Pro: } 24 \%\end{array}$ & $\begin{array}{l}\text { Diabetes diet designed in } \\
\text { accordance with current } \\
\text { diabetes dietary guideline } \\
\text { CHO: } 42 \% \text {, Fat: } 34 \% \\
\text { Pro: } 20 \%\end{array}$ & $\begin{array}{l}\text { FBG } \\
\text { Insulin } \\
\text { HbA1c } \\
\text { HOMA- } \\
\text { IR }\end{array}$ & $\begin{array}{l}\text { Patients with type } 2 \\
\text { diabetes }\end{array}$ \\
\hline $\begin{array}{l}\text { Lindeberg } \\
(2007)\end{array}$ & 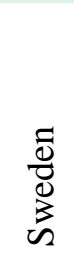 & 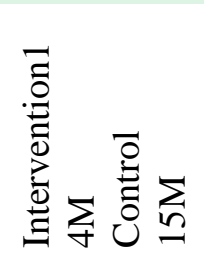 & 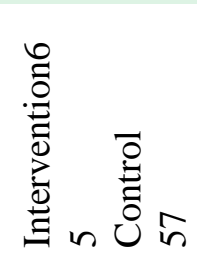 & 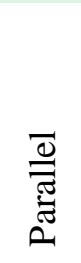 & ১ & $\begin{array}{l}\text { Paleolithic diet } \\
\text { CHO: } 40.2 \% \text {, Fat: } \\
\text { 26.9\%, Pro: } 27.9 \%\end{array}$ & $\begin{array}{l}\text { Consensus (Mediterranean- } \\
\text { like) diet } \\
\text { CHO: } 51.7 \% \text {, Fat: } 24.7 \% \text {, } \\
\text { Pro: } 20.5 \%\end{array}$ & $\begin{array}{l}\text { FBG } \\
\text { 2h PBG } \\
\text { Insulin } \\
\text { HbA1c } \\
\text { HOMA- } \\
\text { IR }\end{array}$ & $\begin{array}{l}\text { Ischemic heart disease } \\
\text { patients with waist } \\
\text { circumference }>94 \mathrm{~cm} \text { and } \\
\text { increased blood glucose or } \\
\text { known diabetes }\end{array}$ \\
\hline
\end{tabular}

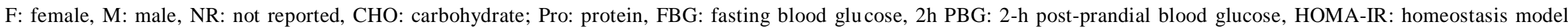
assessment for insulin resistance, HbA1c: Hemoglobin A1c, MetS: metabolic syndrome 
Table 2- Risk of bias assessment for included randomized controlled clinical trails

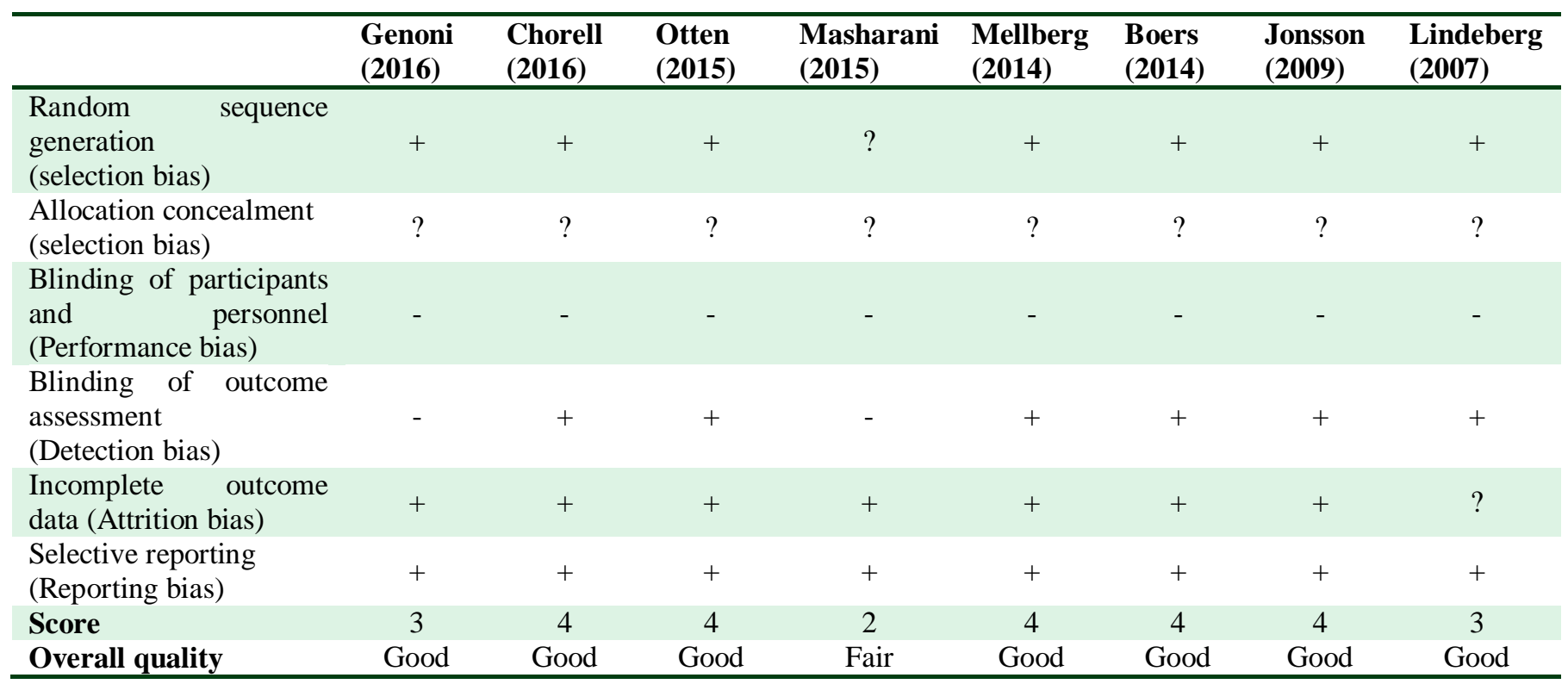

\section{Discussion}

To best of our knowledge, the present systematic review and meta-analysis is the first study that assessed the effect of PD pattern on the glycemic control. Our meta-analysis of eight RCTs showed that this dietary pattern had no significant effects on glycemic markers, although reduction was observed in FBG levels.

The PD recommends avoidance of processed food, refined sugars, legumes, dairy, grains, and cereals. Instead, it advocates for the consumption plant foods including fruit, vegetables, nuts, roots and grass-fed meat, wild fish, and "healthy" saturated fat (O'dea, 1984). It was reported that PD could improve the insulin sensitivity and prevent insulin resistance (Lindeberg et al., 2003). This pattern may be more satiating among patients with T2DM; this can be resulted from significant increase in plasma glucagon-like peptide-1 (GLP1), glucose-dependent insulinotropic peptide, and peptide YY (PYY) following the PD consumption. The changes of these hormone levels were associated with a higher satiety score (Bligh et al.,
2015). Moreover, the higher protein content and amount of fruit and vegetable caused by its high contents of water (Davy et al., 2008), may promote the satiating effect of the Paleolithic dietary pattern (Beasley et al., 2009).

In comparison with regular diabetes diet, PD was lower in cereals, dairy products, potatoes, beans, and bakery foods but higher in fruits, vegetables, meat, and eggs. Therefore, it seems that this diet has lower total energy, carbohydrate, dietary glycemic load, fiber, and saturated fatty acids, but higher unsaturated fatty acids and dietary cholesterol (Klonoff, 2009). Moreover, PD provides higher amounts of protein, which can promote the weight loss compared with high-carbohydrate diets and consequently lead to favorable effects on risk reduction for metabolic diseases (Lasker et al., 2008). However, it must be noted that in absence of changes in weight or energy intake, the PD is as efficient in improving the glucose, insulin, or HOMA-IR as a standard diet. Thus, even very short deficits in energy balance can improve the metabolic parameters (Gannon et al., 1996). 
Previous meta-analysis reported that PD, compared with control diets, resulted in greater short-term improvements for FBG $(20.16 \mathrm{mmol} / \mathrm{L}$; 95\% CI: 20.44, $0.11 \mathrm{mmol} / \mathrm{L}$ ) (Manheimer et al., 2015). However, only four studies with short duration were included in this review; therefore, the results are probably unreliable.

Lack of a significant decrease in levels of FBG, insulin, and HOMA-IR in our study may be partly explained by the fact that most of the participants had normal glucose tolerance at the baseline, which could reduce the possibility of improving the metabolic status (Mellberg et al., 2014). Indeed, most studies over the effect of PD on insulin and insulin sensitivity were conducted among participants with a more pronounced metabolic dysfunction. This indicates an improvement in the glucose tolerance and cardiovascular risk markers (Jönsson et al., 2010).

Glucose tolerance did not improve after reduction of carbohydrate intake in earlier dietary investigations (Noakes et al., 2006, Pittas et al., 2006). Diets with low glycemic load such as PD pattern can reduce the metabolic consequences of glucose intolerance; for example, they can delay the manifestation of diabetes, without necessarily improving the glucose tolerance (Gannon and Nuttall, 2006, Reaven, 2005). The potential impact of high protein intakes over long term periods as well as its association with hyperinsulinemia and insulin resistance require further investigations (Rietman et al., 2014). However, weight loss may be a more significant modifier of metabolic syndrome risk compared with the type or quantity of protein intake (Hill et al., 2015).

Some limitations exist in the present systematic review and meta-analysis that must be mentioned. First, there were not many studies on the PD and therefore, the total meta-analysis sample size was small. Second, the included trials were conducted among the individuals with different metabolic characteristics (i.e., patients with T2DM, postmenopausal, ischemic heart disease, metabolic syndrome, and healthy people). In addition, the intervention duration was various in different studies which might lead to different results. On the other hand, the results of most studies were not adjusted for confounding factors such as physical activity (Bassuk and Manson, 2005, Boulé et al., 2001) and smoking (Eliasson, 2003), which were associated with glycemic indices. This metaanalysis had several strengths. It evaluated the effect of PD on several glycemic markers. Additionally, a comprehensive and systematical search was conducted to find all the relevant published literatures and subsequently Egger's test and Begg's test showed that the findings were not affected by publication bias.

\section{Conclusions}

The PD had no significant effect on glycemic markers; therefore, it is difficult to make strong conclusions about the long term benefits of this diet considering the short duration of interventions and small sample sizes of the included studies. Accordingly, additional studies are required to assess the anti-hyperglycemic effect of the PD in patients with hyperglycemia. Since avoidance of refined and extra sugars and processed, energydense food is in accordance with the available guidelines, more RCTs with more patients in longer period of time are required to determine its beneficial effects over other dietary advices.

\section{Authors' contributions}

Salehi-Abargouei A and Mohammadi M designed the research; Mohammadi $M$ and Mohammadi $\mathrm{H}$ conducted the systematic search and study selection; Mohammadi M, Mohammadi $\mathrm{H}$ and Ramezani-Jolfaie N extracted data; SalehiAbargouei A and Mohammadi $\mathrm{M}$ analyzed data; Mohammadi M, Mohammadi $\mathrm{H}$ and Ghaedi $\mathrm{H}$ wrote the manuscript; Salehi-Abargouei A and Ramezani-Jolfaie $\mathrm{N}$ edited the manuscript and all authors read and approved the final manuscript. 


\section{Conflict of interest}

The study was funded by Nutrition and Food Security research center, Shahid Sadoughi

\section{References}

Ahangarpour A, et al. 2017. Effects of hydroalcoholic extract of Rhus coriaria seed on glucose and insulin related biomarkers, lipid profile, and hepatic enzymes in nicotinamidestreptozotocin-induced type II diabetic male mice. Research in pharmaceutical sciences. 12 (5): 416.

Andersson J, et al. 2016. Left ventricular remodelling changes without concomitant loss of myocardial fat after long-term dietary intervention. International journal of cardiology. 216: 92-96.

Association AD 2016. 3. Foundations of care and comprehensive medical evaluation. Diabetes care. 39 (Supplement 1): S23-S35.

Bassuk SS \& Manson JE 2005. Epidemiological evidence for the role of physical activity in reducing risk of type 2 diabetes and cardiovascular disease. Journal of applied physiology. 99 (3): 1193-1204.

Baumgartner S, et al. 2009. The impact of the stone age diet on gingival conditions in the absence of oral hygiene. Journal of periodontology. 80 (5): 759-768.

Beasley JM, et al. 2009. Associations between macronutrient intake and self-reported appetite and fasting levels of appetite hormones: results from the optimal macronutrient intake trial to prevent heart disease. American journal of epidemiology. 169 (7): 893-900.

Bligh HFJ, et al. 2015. Plant-rich mixed meals based on Palaeolithic diet principles have a dramatic impact on incretin, peptide YY and satiety response, but show little effect on glucose and insulin homeostasis: an acute-effects randomised study. British journal of nutrition. 113 (4): 574-584.

Blomquist C, et al. 2017a. Attenuated low-grade inflammation following long-term dietary intervention in postmenopausal women with obesity. Obesity 25 (5): 892-900.
University of Medical Sciences, Yazd, Iran. There is no conflict of interest to report for present study.

Blomquist C, et al. 2017b. Decreased lipogenesispromoting factors in adipose tissue in postmenopausal women with overweight on a Paleolithic-type diet. European journal of nutrition.

Boers I, et al. 2014. Favourable effects of consuming a Palaeolithic-type diet on characteristics of the metabolic syndrome: a randomized controlled pilotstudy. Lipids health disease. 13: 160.

Boraxbekk CJ, et al. 2015. Diet-Induced Weight Loss Alters Functional Brain Responses during an Episodic Memory Task. Obesity facts. 8 (4): 261272.

Boulé NG, Haddad E, Kenny GP, Wells GA \& Sigal RJ 2001. Effects of exercise on glycemic control and body mass in type 2 diabetes mellitus: a meta-analysis of controlled clinical trials. Journal of the American medical association. 286 (10): 12181227.

Carson AP, et al. 2016. Do glycemic marker levels vary by race? Differing results from a crosssectional analysis of individuals with and without diagnosed diabetes. BMJ open diabetes research \& care. 4 (1): e000213.

Chan GC \& Tang SC 2015. Diabetic nephropathy: landmark clinical trials and tribulations. Nephrology dialysis transplantation. 31 (3): 359-368.

Chorell E, et al. 2016. Plasma metabolomic response to postmenopausal weight loss induced by different diets. Metabolomics. 12 (5).

Cordain L 2002. The nutritional characteristics of a contemporary diet based upon Paleolithic food groups. Journal of American neutraceutical association. 5: 15-24.

Davy BM, Dennis EA, Dengo AL, Wilson KL \& Davy KP 2008. Water consumption reduces energy intake at a breakfast meal in obese older adults. 
Journal of the American dietetic association. 108 (7): 1236-1239.

Eliasson B 2003. Cigarette smoking and diabetes. Progress in cardiovascular diseases. 45 (5): 405413.

Evert AB, et al. 2014. Nutrition therapy recommendations for the management of adults with diabetes. Diabetes care. 37 (Supplement 1): S120-S143.

Frassetto LA, Schloetter M, Mietus-Synder M, Morris RC, Jr. \& Sebastian A 2009. Metabolic and physiologic improvements from consuming a paleolithic, hunter-gatherer type diet. European journal clinical nutrition. 63 (8): 947-955.

Frassetto LA, Shi L, Schloetter M, Sebastian A \& Remer T 2013. Established dietary estimates of net acid production do not predict measured net acid excretion in patients with Type 2 diabetes on Paleolithic-Hunter-Gatherer-type diets. European journal clinical nutrition. 67 (9): 899-903.

Gannon MC \& Nuttall FQ 2006. Control of blood glucose in type 2 diabetes without weight loss by modification of diet composition. Nutrition \& metabolism. 3 (1): 16.

Gannon MC, et al. 1996. Effect of 24 hours of starvation on plasma glucose and insulin concentrations in subjects with untreated noninsulin-dependent diabetes mellitus. Metabolism. $\mathbf{4 5}$ (4): 492-497.

Genoni A, Lo J, Lyons-Wall P \& Devine A 2016a. Compliance, palatability and Feasibility of Paleolithic and Australian guide to healthy eating diets in healthy women: A 4-week dietary intervention. Nutrients. 8 (8).

Genoni A, Lyons-Wall P, Lo J \& Devine A 2016 b. Cardiovascular, metabolic effects and dietary composition of ad-Libitum Paleolithic vs. Australiang guide to healthy eating diets: A 4-week eandomised trial. Nutrients. 8 (5).

Higgins JP \& Green S 2011. Cochrane handbook for systematic reviews of interventions. John Wiley \& Sons.
Hill AM, Jackson KAH, Roussell MA, West SG \& Kris-Etherton PM 2015. Type and amount of dietary protein in the treatment of metabolic syndrome: a randomized controlled trial. American journal of clinical nutrition. 102 (4): 757-770.

Jönsson T, et al. 2009. Beneficial effects of a Paleolithic diet on cardiovascular risk factors in type 2 diabetes: a randomized cross-over pilot study. Cardiovascular diabetology. 8 (1): 35.

Jönsson T, Granfeldt Y, Erlanson-Albertsson C, Ahrén B \& Lindeberg S 2010. A paleolithic diet is more satiating per calorie than a mediterranean-like diet in individuals with ischemic heart disease. Nutrition \& metabolism. 7 (1): 85.

Jonsson T, Granfeldt Y, Lindeberg S \& Hallberg AC 2013. Subjective satiety and other experiences of a Paleolithic diet compared to a diabetes diet in patients with type 2 diabetes. Nutrition journal. 12: 105.

Klonoff DC 2009. The beneficial effects of a Paleolithic diet on type 2 diabetes and other risk factors for cardiovascular disease. SAGE Publications.

Lasker DAW, Evans EM \& Layman DK 2008. Moderate carbohydrate, moderate protein weight loss diet reduces cardiovascular disease risk compared to high carbohydrate, low protein diet in obese adults: A randomized clinical trial. Nutrition \& metabolism. 5 (1): 30.

Lee JE, et al. 2017. A Multimodal, Nonpharmacologic Intervention Improves Mood and Cognitive Function in People with Multiple Sclerosis. Journal of the American College of Nutrition. 36 (3): 150-168.

Lindeberg S, Cordain L \& Eaton SB 2003. Biological and clinical potential of a palaeolithic diet. Journal of nutritional \& environmental medicine. 13 (3): 149-160.

Lindeberg S, et al. 2007. A Palaeolithic diet improves glucose tolerance more than a Mediterranean-like diet in individuals with 
ischaemic heart disease. Diabetologia. 50 (9): 17951807.

Manheimer EW, van Zuuren EJ, Fedorowicz Z \& Pijl H 2015. Paleolithic nutrition for metabolic syndrome: systematic review and meta-analysis. The American journal of clinical nutrition. 102 (4): 922-932.

Masharani U, et al. 2015. Metabolic and physiologic effects from consuming a hunter-gatherer (Paleolithic)-type diet in type 2 diabetes. European journal of clinical nutrition. 69 (8): 944-948.

Mellberg C, et al. 2014. Long-term effects of a Palaeolithic-type diet in obese postmenopausal women: a 2-year randomized trial. European journal of clinical nutrition. 68 (3): 350-357.

Metzgar M, Rideout TC, Fontes-Villalba M \& Kuipers RS 2011. The feasibility of a Paleolithic diet for low-income consumers. Nutrition research. 31 (6): 444-451.

Noakes M, et al. 2006. Comparison of isocaloric very low carbohydrate/high saturated fat and high carbohydrate/low saturated fat diets on body composition and cardiovascular risk. Nutrition \& metabolism. 3 (1): 7.

O'dea K 1984. Marked improvement in carbohydrate and lipid metabolism in diabetic Australian Aborigines after temporary reversion to traditional lifestyle. Diabetes. 33 (6): 596-603.

Osterdahl M, Kocturk T, Koochek A \& Wandell PE 2008. Effects of a short-term intervention with a paleolithic diet in healthy volunteers. European journal of clinical nutrition. 62 (5): 682-685.

Otten J, et al. 2016a. Strong and persistent effect on liver fat with a Paleolithic diet during a two-year intervention. International journal of obesity. 40 (5): 747-753.

Otten J, et al. 2016b. Effects of a paleolithic diet with and without supervised exercise on liver fat and insulin sensitivity: a randomised controlled trial in individuals with type 2 diabetes. Diabetologia. 59: S10-S10.
Parham M, et al. 2014. Effects of pistachio nut supplementation on blood glucose in patients with type 2 diabetes: a randomized crossover trial. Review of diabetic studies. 11 (2): 190.

Picot J, et al. 2012. The preferred reporting Items for systematic reviews and meta-analyses checklist.

Pittas AG, et al. 2006. The effects of the dietary glycemic load on type 2 diabetes risk factors during weight loss. Obesity. 14 (12): 2200-2209.

Qu H-Q, Li Q, Rentfro AR, Fisher-Hoch SP \& McCormick JB 2011. The definition of insulin resistance using HOMA-IR for Americans of Mexican descent using machine learning. PloS one. 6 (6): e21041.

Reaven GM 2005. The insulin resistance syndrome: definition and dietary approaches to treatment. Annual review of nutrition. 25: 391-406.

Rietman A, Schwarz J, Tomé D, Kok FJ \& Mensink M 2014. High dietary protein intake, reducing or eliciting insulin resistance? European journal of clinical nutrition. 68 (9): 973-979.

Ryberg M, et al. 2013. A Palaeolithic-type diet causes strong tissue-specific effects on ectopic fat deposition in obese postmenopausal women. Journal of internal medicine. 274 (1): 67-76.

Sandberg S, et al. 2012. Does a Paleolithic-type diet have a beter effect that a conventional low-fat diet in achieving long-term weight-loss among obese post-menopausal women? International journal of behavioral medicine. 19: S227-S228.

Singh RB, et al. 2012. Effect of low W-6/W-3 fatty acid ratio Paleolithic style diet in patients with acute coronary syndromes: A randomized, single blind, controlled trial. World heart journal. 4 (1): 71-84.

Stomby A, et al. 2015. Diet-induced weight loss has chronic tissue-specific effects on glucocorticoid metabolism in overweight postmenopausal women. International journal obesity. 39 (5): 814-819.

Tobias A 1999. Assessing the influence of a single study in the meta-anyalysis estimate. Stata technical bulletin. 8 (47). 


\section{Trexler ET, Smith MM, Sommer AJ, Starkoff BE} \& Devor ST 2013. Paleolithic Diet Is Associated With Unfavorable Changes To Blood Lipids In Healthy Subjects. Medicine and science in sports and exercise. 45 (5): 659-659.

Whalen KA, et al. 2017. Paleolithic and
Mediterranean Diet Pattern Scores Are Inversely Associated with All-Cause and Cause-Specific Mortality in Adults. Journal of nutrition. 147 (4): 612-620.

WHO 2014. Global status report on alcohol and health, 2014. World Health Organization. 